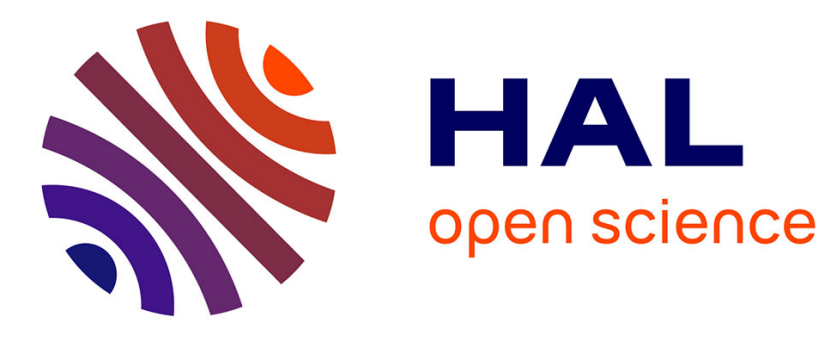

\title{
Enhanced Excitability of the Neonatal Rat Hippocampus After Acute Exposure to Ethanol
}

\author{
Nailya Lotfullina, Andrey Zakharov, Roustem Khazipov
}

\section{To cite this version:}

Nailya Lotfullina, Andrey Zakharov, Roustem Khazipov. Enhanced Excitability of the Neonatal Rat Hippocampus After Acute Exposure to Ethanol. BioNanoScience, 2017, 7 (1), pp.119-122. 10.1007/s12668-016-0321-y . hal-01962313

\section{HAL Id: hal-01962313 \\ https://hal-amu.archives-ouvertes.fr/hal-01962313}

Submitted on 20 Dec 2018

HAL is a multi-disciplinary open access archive for the deposit and dissemination of scientific research documents, whether they are published or not. The documents may come from teaching and research institutions in France or abroad, or from public or private research centers.
L'archive ouverte pluridisciplinaire HAL, est destinée au dépôt et à la diffusion de documents scientifiques de niveau recherche, publiés ou non, émanant des établissements d'enseignement et de recherche français ou étrangers, des laboratoires publics ou privés.

\section{(c)(1)}

Distributed under a Creative Commons Attribution| 4.0 International License 


\title{
Enhanced Excitability of the Neonatal Rat Hippocampus After Acute Exposure to Ethanol
}

\author{
Nailya Lotfullina ${ }^{1,2,3}$ (D) Andrey Zakharov ${ }^{1,4} \cdot$ Roustem Khazipov ${ }^{1,2,3}$
}

Published online: 11 October 2016

(C) Springer Science+Business Media New York 2016

\begin{abstract}
Enhanced excitability manifested by seizures and epilepsy is one of the characteristic features of the fetal alcohol spectrum disorders (FASD). Here, we examined network excitability using a high-potassium model in the hippocampal slices prepared from the postnatal days of P7-9 rats treated with ethanol. Ethanol was administered at $6 \mathrm{~g} / \mathrm{kg}$ intraperitoneally $12 \mathrm{~h}$ before the slice preparation. The extracellular field potential recordings from the hippocampal slices using multishank silicon probes placed along CA3-CA1 axis were performed in the interface chamber. We found that elevation of the extracellular potassium from 3.5 to $6 \mathrm{mM}$ evoked seizure-like clonic or tonic-clonic discharges in $77 \%$ of the slices from the ethanol-treated animals and only in $15 \%$ of the slices from the control animals. Further elevation of the extracellular potassium to $8.5 \mathrm{mM}$ evoked epileptiform activity in 92 and $69 \%$ of the slices from the ethanol-treated and the control animals, respectively. The current source density profile and the multiple unit activity analysis pointed on the CA3 hippocampal region as a generator of the epileptiform activity. Thus, the hippocampal slices from the ethanol-treated neonatal rats display enhanced excitability and could serve as a FASD model to study the early epileptiform transformations following exposure to ethanol.
\end{abstract}

Nailya Lotfullina

nzlotfullina@gmail.com

1 Laboratory of Neurobiology, Kazan Federal University, 18 Kremlevskaya str, Kazan 420008, Russia

2 INMED - INSERM U901, 163 avenue de Luminy, Marseille 13273, France

3 Aix-Marseille University, Marseille 13273, France

4 Department of Physiology, Kazan State Medical University, 420012 Kazan, Russia
Keywords Alcoholism · Fetal alcohol syndrome · Hippocampus $\cdot$ Seizure $\cdot$ Neonate

\section{Introduction}

Fetal alcohol spectrum disorders (FASD) is a common term used to describe a range of adverse developmental outcomes that may occur in a person whose mother was consuming alcohol during pregnancy. FASD is associated with several comorbidities including epilepsy. Seizures are observed with a frequency of 3-21\% in children with FASD [1]. The mechanisms underlying the epileptic phenomena associated with FASD are not fully understood. Carlen and colleagues have recently reported that 1 st trimester equivalent alcohol exposure in pregnant mice dams leads to an enhanced excitability in hippocampal slices prepared from their springs, manifested by the enhancement of the sharp waves, a shift in the excitatory/inhibitory balance towards excitation and increased excitability of CA3 pyramidal cells [2]. Whether 3rd trimester equivalent alcohol exposure, known to be associated with massive neuroapoptosis and long-term alterations in hippocampal functions [3, 4], leads to an enhanced hippocampal excitability remains unknown, however. Here, we addressed this question through the exploration of the excitability using an elevated potassium model in the hippocampal slices prepared from the rat pups shortly after the exposure to ethanol.

\section{Material and Methods}

This work has been carried out in accordance with EU Directive 2010/63/EU for animal experiments and all the protocols were approved by INSERM (N007.08.01) and KSMU (N9-2013). Wistar rats of both sexes from postnatal days (P) 
7-9 were used. Ethanol was administered intraperitoneally at a dose of $6 \mathrm{~g} / \mathrm{kg}$ (20\% normal saline solution). The control animals received the same volume of saline. After the treatment, both the ethanol-treated and the control pups were kept in a thermostated box at $36{ }^{\circ} \mathrm{C}$. Twelve hours after the ethanol or the saline administration, the animals were anesthetized with isoflurane, decapitated, and the brains were rapidly removed to oxygenated $(95 \%$ O2-5 \% CO2) ice-cold $\left(2-5{ }^{\circ} \mathrm{C}\right)$ artificial cerebrospinal fluid (ACSF) of the following composition (in $\mathrm{mM}$ ): $\mathrm{NaCl} 126, \mathrm{KCl} 3.5, \mathrm{CaCl} 2$ 2, $\mathrm{MgCl} 2$ 1.3, NaHCO3 25, NaH2PO4 1.2, and glucose 11 ( $\mathrm{pH} 7.4)$. The six hundred- $\mu \mathrm{m}$-thick horizontal slices were cut using a Vibratome (VT 1000E; Leica, Nussloch, Germany). The slices were kept in oxygenated ACSF at room temperature $\left(20-22{ }^{\circ} \mathrm{C}\right)$ for at least $1 \mathrm{~h}$ before use. For recordings, the slices were placed into a modified interface chamber [5] on a plastic mesh with 1-mm high perfusion space underneath the mesh and, on the inner side, they were superfused with oxygenated ACSF at $33.5-34{ }^{\circ} \mathrm{C}$ at a flow rate of $2-4 \mathrm{ml} / \mathrm{min}$. The recordings were performed simultaneously from a pair of the control and the post-alcohol slices. The extracellular recordings of the local field potentials (LFP) and the multiple unit activity (MUA) were performed using 16 shank silicon probes with $100-\mu \mathrm{m}$ separation distance between the shanks. The data were stored in PC and were analyzed using Matlab routines. The data are expressed as mean $\pm \mathrm{SE}$; the level of significance $p$ was set at 0.05 .

\section{Results and Discussion}

This report is based on the recordings from the 26 hippocampal slices prepared from the P7-9 rat pups including 13 slices from the ethanol-treated and 13 slices from the control animals. Under control conditions, all the slices prepared from both the control and the ethanol-treated rat pups displayed spontaneous giant depolarizing potentials (GDPs), alterations to which are described in the companion paper (this issue). Elevation of the extracellular concentration of potassium from 3.5 to $6 \mathrm{mM}$ evoked epileptiform discharges in the majority of the slices (77\%) from the P7-9 ethanol-treated animals (10/13 slices) and in $15 \%$ of the slices from the P7-9 control animals (2/13 slices) (Fig. 1). The high-potassium-induced discharges were characterized either by recurrent clonic-like bursting or tonicclonic-like electrographic phenotype. The clonic-like bursts occurring at $0.1-1.5 \mathrm{~Hz}$ were composed of multiple population spikes, recruiting most of the neuronal firing of CA3 and CA1 neurons, and regularly. The tonic-clonic episodes typically started with large amplitude population spikes followed by population spikes occurring initially at $10-20 \mathrm{~Hz}$ and slowing down through the tonic phase, with further transition to the clonic-like discharges. The current source and multiple unit density analysis indicated that the CA3 region heralds the population activity and suggested activation of the recurrent collateral synapses and the Schaffer collaterals in the hippocampal network synchronization (Fig. 1d, e). In the CA3 region, the population spikes were characterized by a sink (1) in the CA3 pyramidal cell layer (Fig. 1e), which coincided with a burst of the CA3 multiple unit activity MUA (Fig. 1f) suggesting that it is generated by the summation of the somatic action currents in the nearby CA3 pyramidal cells. CA3 sink 1 was followed by sink 2 in stratum radiatum of $\mathrm{CA} 3$, likely generated by the recurrent collateral synapses (Fig. 1d). At about $10 \mathrm{~ms}$ delay, sinks 3 and 4 occurred in $\mathrm{CA} 1$ region in strata pyramidale and radiatum, respectively. Sink 3 coincided with the MUA burst in the CA1 pyramidal cell layer and thus was likely generated by the summation of CA1 units as homologous sink 1 in CA3. Sink 4 was likely a result of activation of CA3-CA1 Schaffer collateral synapses and CA1-CA1 collaterals [6]. Together, these results indicate that the population discharges were initiated in the $\mathrm{CA} 3$ region, were supported by the local excitatory circuits, and drove the CA1 region.

Further increase in the extracellular potassium concentration to $8.5 \mathrm{mM}$ evoked epileptiform activity in $92 \%$ of the slices from P7-9 ethanol-treated rats (12/13) and in $69 \%$ of the slices from P7-9 control rats (9/13) (Fig. 1b). Interestingly, none of the slices prepared from the P5-6 ethanol-treated or control animals displayed epileptiform activity after the extracellular potassium elevation to $6 \mathrm{mM}$, the increase in the extracellular potassium concentration to $8.5 \mathrm{mM}$ triggered the epileptiform events in $25 \%$ of the slices (1/4) both in the control and the ethanol-exposed rats. In slices prepared from P18-21 rats, epileptiform activity was observed in $14 \%(1 / 7)$ from control and $43 \%$ (3/7) from ethanol-exposed rats after elevation of the extracellular potassium concentration to $6 \mathrm{mM}$ and in $43 \%$ (3/7) of slices from both groups after elevation of potassium to $8.5 \mathrm{mM}$ (Fig. 1b). These findings are in keeping with the bell-shaped developmental profile of seizure-like activity in the high-potassium model [7], and they indicate on increased excitability in slices prepared from the ethanol-treated animals, which is most prominent in P7-9 animals.

We also explored the acute effects of ethanol in slices prepared from P7-9 control rats. In this series of experiments, epileptiform events were evoked by elevation of extracellular potassium to $8.5 \mathrm{mM}$ in the absence of ethanol in $80 \%(4 / 5)$ of slices that was similar to the seizure occurrence in the series of experiments described above. In the presence of ethanol (100 mM), seizure-like activity was evoked by elevated to 8.5-mM extracellular potassium only in $20 \%(1 / 5)$ of slices. Interestingly, following washout of ethanol in the presence of elevated potassium $(8.5 \mathrm{mM})$ epileptiform activity was observed in $80 \%$ of slices (4/5). These findings indicate that ethanol exerts acute inhibitory actions on the epileptiform activities. However, slices prepared from the ethanol-treated 
Fig. 1 Increased occurrence of the epileptiform activity in the hippocampal slices prepared from the ethanol-treated rat pups. a The extracellular field potential recording from the hippocampal CA3 pyramidal cell layer in the slices prepared from the ethanol-treated $(6 \mathrm{~g} / \mathrm{kg}$, i.p., $12 \mathrm{~h}$ prior to the slice preparation) and the control P7 rats. The extracellular potassium is elevated up to $6 \mathrm{mM}$ b The occurrence of the seizurelike activity in the hippocampal slices prepared from the P5-6, P7-9, and P 18-21 ethanolexposed and control rats at 6 and $8.5 \mathrm{mM}$ extracellular potassium concentrations. The pooled data from 4 pairs of the P5-6 slices, 13 pairs of the slices prepared from the P7-9, and 7 pairs from P18-21 of control and ethanoltreated rats. c A schematic illustration of the electrode placement in the hippocampal slice. d. The local field potential traces (LFP) overlaid on the current source density (CSD) map of a seizure-like tonic-clonic discharge evoked by $6 \mathrm{mM}$ extracellular potassium in a slice prepared from a $\mathrm{P} 7$ ethanol-treated rat. e-f CA1 population spike triggered average of the LFP and the CSD (e) and the MUA density (f) a $\left[\mathrm{K}^{+}\right]_{0}=6 \mathrm{mM}$

Post-Ethanol (P7)

CA3 pyr.cell layer LFP
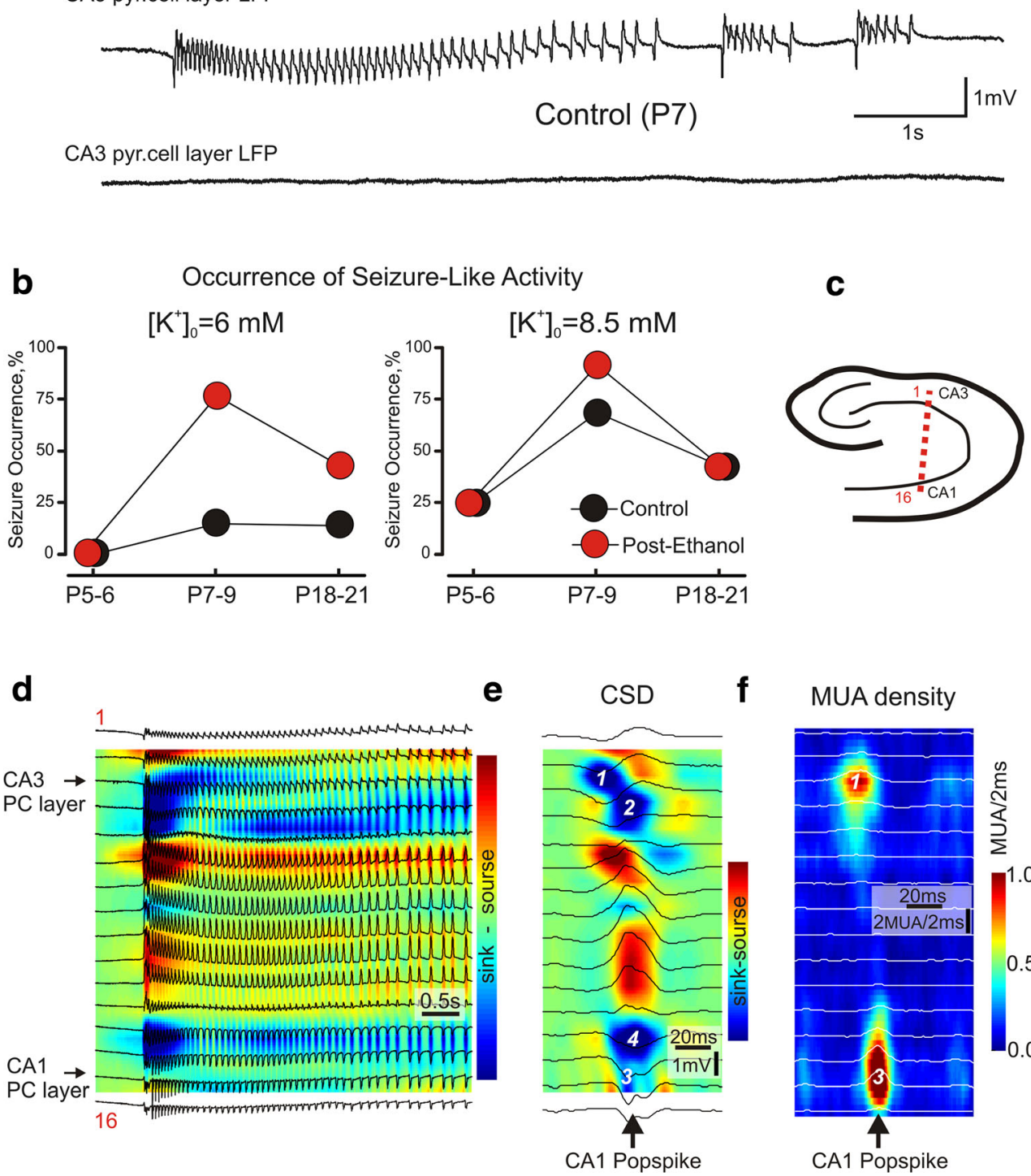

f

MUA density

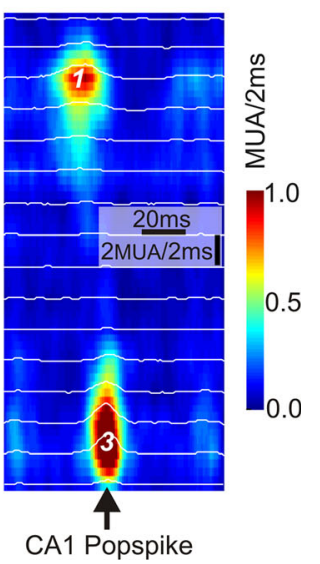

rats $12 \mathrm{~h}$ after ethanol administration and which were incubated in the ethanol-free ACSF displayed enhanced excitability (see above) indicating that in addition to the acute seizuresuppressing effect, ethanol also exerts delayed pro-epileptic actions which are most prominent in P7-9 age group.

\section{Conclusions}

Thus, 3rd trimester equivalent alcohol exposure in the rat model results in a robust increase in the hippocampal excitability revealed by almost a fivefold increase of the occurrence of seizure-like activity in the high-potassium model in the slices prepared from the rat pups $12 \mathrm{~h}$ after the ethanol exposure. Our results suggest that the epileptiform transformations, which are characteristic of FASD, start emerging shortly after the alcohol exposure and may reflect an impairment of the GABAergic mechanisms reported previously [8].

Acknowledgments This work was supported by INSERM (LIA to RK), the Program of Competitive Growth of Kazan Federal University and the subsidy allocated to Kazan Federal University for the state assignment in the sphere of scientific activities.

\section{References}

1. Nicita, F., Verrotti, A., Pruna, D., Striano, P., Capovilla, G., Savasta, S., et al. (2014). Seizures in fetal alcohol spectrum disorders: evaluation of clinical, electroencephalographic, and neuroradiologic features in a pediatric case series. Epilepsia, 55, e60-e66.

2. Krawczyk, M., Ramani, M., Dian, J., Florez, C. M., Mylvaganam, S., Brien, J., et al. (2016). Hippocampal hyperexcitability in fetal alcohol 
spectrum disorder: pathological sharp waves and excitatory/inhibitory synaptic imbalance. Experimental Neurology, 280, 70-79.

3. Ikonomidou, C., Bittigau, P., Ishimaru, M. J., Wozniak, D. F., Koch, C., Genz, K., et al. (2000). Ethanol-induced apoptotic neurodegeneration and fetal alcohol syndrome. Science, 287, 1056-1060.

4. Olney, J. W. (2014). Focus on apoptosis to decipher how alcohol and many other drugs disrupt brain development. Frontiers in Pediatrics, 2,81 .

5. Tsintsadze, V., Minlebaev, M., Suchkov, D., Cunningham, M. O., Khazipov, R. (2015). Ontogeny of kainate-induced gamma oscillations in the rat CA3 hippocampus in vitro. Frontiers in Cellular Neuroscience, 9, 195.
6. Crepel, V., Khazipov, R., Ben-Ari, Y. (1997). Blocking GABA(A) inhibition reveals AMPA- and NMDA-receptor-mediated polysynaptic responses in the CA1 region of the rat hippocampus. Journal of Neurophysiology, 77, 2071-2082.

7. Khazipov, R., Khalilov, I., Tyzio, R., Morozova, E., Ben Ari, Y., Holmes, G. L. (2004). Developmental changes in GABAergic actions and seizure susceptibility in the rat hippocampus. European Journal of Neuroscience, 19, 590-600.

8. Everett, J. C., Licon-Munoz, Y., Valenzuela, C. F. (2012). Effects of third trimester-equivalent ethanol exposure on $\mathrm{Cl}(-)$ co-transporter expression, network activity, and GABAergic transmission in the CA3 hippocampal region of neonatal rats. Alcohol, 46, 595-601. 